\title{
Los conflictos de intereses en radiología. Consideracio- nes prácticas
}

\author{
César García M.', Cristián García B. ${ }^{2}$, Enrique Bosch $0 .{ }^{2}$, Karla Möenne B. ${ }^{2}$
}

1. Médico Radiólogo. Jubilado Depto. de Radiologia, Clínica Alemana. Santiago, Chile.

2. Comité de Ética Sociedad Chilena de Radiología. Santiago, Chile.

\section{¿Qué son los conflictos de intereses?}

Un conflicto de interés se define como un conjunto de condiciones y circunstancias que pueden influenciar indebidamente el juicio profesional, remplazando total o parcialmente el interés primario por un interés secundario. El conflicto de interés se refiere sobre todo a una "situación" y no necesariamente a un "comportamiento", que puede afectar el bienestar del paciente.

En toda actividad humana existe la posibilidad de enfrentar conflictos de intereses. Esto incluye el ejercicio de la Radiología, donde interactuamos con empresas y diversos actores sociales. Si se produce un conflicto de interés en el curso de esta interacción, corremos el riesgo que nuestra decisión para resolverlo pueda anteponer consideraciones distintas a la adecuada atención y bienestar del paciente. Por otra parte, en la actualidad todo esto se produce en un marco de pacientes mejor informados y más empoderados.

La actividad médica está expuesta a la posibilidad del conflicto y a la necesidad de escoger entre distintas opciones. Al producirse el conflicto entre valores primordiales, ninguna opinión o guía diseñados para apoyo de decisiones puede prevenir una trasgresión ética, debido a que la resolución de cada conflicto implica algún grado de compromiso con valores importantes que dependerán en última instancia e inevitablemente de la formación, creencias y valores personales de cada médico en particular, es decir, de su honestidad e integridad.

Como radiólogos podemos estar expuestos a situaciones potencialmente conflictivas que pueden amenazar la objetividad profesional y generar un conflicto ético. Entre estas destaca la contribución de las empresas a las actividades científicas y docentes lo que constituye un aporte importante e innegable. No encontramos datos precisos de los montos involucrados en nuestro país y, si bien es muy difícil avaluarlos, el aporte de las empresas a la actividad médica por esta vía aparece como significativo.
La relación directa de la industria y los profesionales del área de la Radiología es un proceso complejo en el que los distintos grupos tienen visiones diferentes, a veces contrapuestas. Los médicos tienen el deber de atender a sus pacientes con apego a los principios éticos del profesionalismo médico, centrados en el paciente, lo que incluye defender sus mejores intereses y respetar los principios de beneficencia, no maleficencia. Deben además respetar el principio de autonomía, promover el consentimiento informado y buscar la equidad en la atención médica como parte del principio de justicia. Es necesario involucrar a la industria y sus representantes a través de iniciativas conjuntas con las asociaciones médicas para desarrollar pautas éticas originadas en dos pilares: el primero, basado en el precepto ético del conflicto de intereses, en el que la línea basal para la industria de equipos y productos para la atención médica debe ser lo que resulte mejor para los pacientes y el segundo, la completa divulgación de estos conflictos de intereses y de cómo estos conflictos pueden potencialmente influir en las decisiones, que en último término afectan la atención médica.

Los pacientes y el público en general también juegan un rol importante. En líneas generales el público está cada vez más informado y puede ser capaz de de darse cuenta cuando un médico les está prestando atención médica influenciado por la industria. Con esto se erosiona la confianza en la competencia del médico y se duda si el profesional ubica en primer lugar el beneficio del paciente por sobre cualquier otra consideración.

¿Influyen los regalos y atenciones sobre nuestra autonomía para discernir este tipo de dilemas o disyuntivas?

La respuesta es sí y así ha quedado claro desde el punto de vista de los estudiosos de la ética y de aquellos de las ciencias sociales. Por otra parte, diversas asociaciones médicas han recomendado "conductas apropiadas" para los radiólogos, incluyen- 
do American Medical Association (AMA), American College of Radiology (ACR).

En nuestro país, esta preocupación se ha dado principalmente en la Asociación de Sociedades Científicas-Médicas de Chile (ASOCIMED) que generó un documento con recomendaciones para el control de conflictos de intereses. Anteriormente el problema había sido mencionado en el Código de Ética del Colegio Médico y una referencia muy general aparece en el Código Sanitario. Las recomendaciones de ASOCIMED, asociación a la que la Sociedad Chilena de Radiología pertenece, están basadas en la experiencia internacional y constituyen una propuesta para paliar la carencia de pautas nacionales específicas. Estas están también especificadas en el Código de Ética de La Sociedad Chilena de Radiología.

En las discusiones acerca de los obsequios de la industria, ya sea en las revistas médicas, medios de comunicación o debates políticos, es posible vislumbrar una perspectiva común: el efecto de sesgo que implica aceptar regalos se trata como un tema de elección deliberada. Sin embargo, es interesante lo que deriva de los estudios en grupos, tanto de médicos como de estudiantes de medicina publicados desde las ciencias sociales acerca del sesgo: aun con motivación no somos capaces de permanecer objetivos (componente no intencional), se produce sesgo incluso con instrucciones en contra (componente inconsciente) y tiene un efecto indirecto al sopesar y elegir entre varias alternativas.

La elección deliberada es inconsistente con las investigaciones de las ciencias sociales, las cuales muestran que aun cuando los individuos tratan de ser objetivos, si están presionados para lograr una conclusión en particular, sopesan los argumentos de manera sesgada y favorecen una conclusión específica, ya que sus juicios están sujetos a un sesgo inconsciente y no intencionado de interés personal. A pesar de esta evidencia, los médicos no se perciben a sí mismos como sesgados y niegan que sus decisiones sean influidas por los regalos de la industria. Sin embargo y, muy por el contrario, las publicaciones muestran una fuerte correlación entre beneficios recibidos de parte de la industria, ya sea en forma individual o por instituciones académicas, y el favorecer sus productos.

Los estudios sobre lo que piensan los médicos, avalan la creencia de que los regalos pequeños son éticamente más aceptables que los más valiosos, y sostienen que los obsequios pequeños no afectan el juicio médico con respecto a un producto y no influirían en la elección de éste, como si los médicos hicieran un deliberado intercambio entre el costo del sesgo y el beneficio de la recompensa.

La interacción entre los radiólogos y la industria es de larga data y ha sido un esfuerzo de colabo- ración muy fructífero. Para que esta colaboración siga siendo beneficiosa para pacientes, radiólogos e industria, es necesaria la elaboración o perfeccionamiento de recomendaciones éticas. Resulta imperativo que exista una política de respuesta adecuada al tema de los regalos de la industria, originada en una comprensión real de la psicología de los conflictos de intereses, sin políticas basadas en la interpretación del sesgo como un asunto de elección deliberada, ya que probablemente no serán efectivas si el sesgo es en realidad no intencional e inconsciente y ocurre aún con indicaciones para prevenirlo o evitarlo.

En algunos centros se ha planteado una especie de política de "tolerancia cero" ante los regalos de la industria, basándose específicamente en sus componentes de inconciencia y no intencionalidad, con resguardos muy estrictos para los aportes de la industria a los centros académicos.

Basados en la premisa que la relación con la industria debe contribuir a mejorar el nivel de conocimiento en materias relacionadas al cuidado de la salud, la prestación de servicios de salud o sostenibilidad del sistema de salud, es recomendable que los aportes de la industria sean canalizadas a través de las Instituciones respectivas.

Los médicos que tengan posibles conflictos de interés financiero tales como investigadores, conferencistas, consultores, empleados u otros, no deben comprometer la objetividad de su juicio clínico ni los intereses de los pacientes. Deben revelar sus intereses financieros a sus pacientes y además deben declararlos por escrito al momento de enseñar, dictar una clase o conferencia, presentar un trabajo, o en una publicación. La mayoría de los Congresos científicos exigen hoy a los conferencistas declarar sus conflictos de intereses al comenzar su exposición.

De esta misma manera, los editores de revistas médicas requieren que los autores y los colegas encargados de la revisión revelen cualquier potencial conflicto de interés. Los editores en sí mismos deben estar libres de conflictos de interés.

En nuestro país se firmó en abril del 2017, un acuerdo entre el Colegio Médico de Chile y la Cámara de la Innovación Farmacéutica de Chile sobre "Lineamientos Éticos para evitar conflictos de interés", acuerdo que establece nuevos estándares éticos y de Buenas Prácticas en la interacción entre la industria y los profesionales médicos $y$, por su alcance, sienta un precedente en materia de autorregulación en la región.

En un segundo grupo de los conflictos de intereses están aquellas situaciones donde la indicación de exámenes puede ir acompañada de un estímulo económico. Esto puede ocurrir en prácticas como honorarios por promover productos o servicios de las compañías en conferencias o publicaciones, pago 
por participar en investigaciones financiadas por la industria, comisiones por derivación de pacientes, autorreferencia de pacientes a instalaciones donde el médico tiene intereses económicos, etc. Del mismo modo que los regalos, este tipo de relaciones puede amenazar la objetividad profesional y desencadenar un conflicto ético. En caso de ser necesario, además de revelar estos intereses a los pacientes, los médicos deben establecer normas estrictas para evitar el abuso o prácticas inapropiadas.

\section{Conclusiones}

- Los conflictos de intereses son frecuentes en la práctica médica, incluida la Radiología, y la gran mayoría de ellos no son divulgados.

- La divulgación debería ser la respuesta inicial para enfrentar el problema, seguida de un abordaje del problema.

- En las actividades de educación y difusión para becarios, radiólogos y en especial, a quienes forman radiólogos, debiera incluirse imperativamente el reconocimiento del conflicto de interés como un objetivo, para alcanzar un apropiado enfrentamiento de este tema.

- Ante un conflicto de interés lo primero es visualizarlo y luego considerar recomendaciones de cómo lidiar con ellos, apelando a valores y creencias, para tomar la decisión más apropiada.

\section{Lectura recomendada}

1. García C, Ortega D, Biagini L. Interacciones industria y Radiología: Logros innegables, conflictos de intereses posibles. Los obsequios de la industria. Rev Chil Radiol 2006; 12: 179-185.

2. Conflict of interest policy for the American College of Radiology

https://www.acr.org/-/media/ACR/Files/MemberResources/Volunteer/Conflict-of-Interest-Policy.pdf

3. Canadian Association of Radiologists. White Paper. Professionalism in Radiology.

https://car.ca/wp-content/uploads/ProfessionalismRadiology-White-Paper.pdf

4. Código Ética Sociedad Chilena de Radiología A.G. https://www.sochradi.cl/wp-content/uploads/Codigode-etica-SOCHRADI.pdf

5. Código Ética Colegio Médico de Chile A.G. http://www.colegiomedico.cl/wp-content/ uploads/2018/12/colmed_codigo_etica_2013.pdf

6. Asociación de Sociedades Científicas-Médicas de Chile, 12 de enero de 2005.

https://asocimed.cl/recomendaciones-de-control-deconflicto-de-intereses/

7. Manual de Ética del American College of Physicians, Sexta Edición 2012. Ann Intern Med. 2012;156: 73-104. https://www.acponline.org/system/files/documents/ running_practice/ethics/manual/spanish-ethicsmanual-6th-edition.pdf

García C, et al. Los conflictos de intereses en radiología. Consideraciones prácticas. Rev Chil Radiol 2018; 24(4): 126-128.

*Correo electrónico: Cristián García / cgarciabruce@gmail.com 